\title{
Nuevas aportaciones acerca de las ermitas de Jaén: aproximación al estudio de la Ermita de Santa Isabel
}

\author{
Beatriz Sánchez Justicia * \\ Ana Herranz Sánchez *
}

\begin{abstract}
RESUMEN
Este trabajo intenta determinar el origen y la situación de la Ermita de Santa Isabel, a la vez que hace un breve repaso de algunas de las ermitas situadas extramuros de Jaén, en la zona entre la Puerta de Martos y del Aceituno. El artículo viene derivado de una Intervención Arqueológica de Urgencia que se realizó en verano de 2002 donde aparecieron los cimientos de diversas construcciones que se han identificado con la ermita medieval de Santa Isabel situada en las inmediaciones de la ciudad de Jaén. Se ha intentado contrastar la información arqueológica registrada, con diversas fuentes documentales.
\end{abstract}

PALABRAS CLAVE: Ermita, Medieval, cripta.

\section{INTRODUCCIÓN}

En este breve estudio, queremos presentar la descripción y los resultados de la Intervención Arqueológica que durante el verano de 2002, se realizó en el Barrio de Santa Isabel de Jaén.

La parcela se encuentra ubicada a las afueras de la muralla medieval entre dos de sus prin-

\begin{abstract}
This job trying to determine the origin and the situatión of the Hermit of Santa Isabel, at one time that make a short review of some hermits located extrawall of Jaen, in the zone between Puerta de Martos and Aceituno. The article comes derived of a Urgency Intervetion Archaeological which made in 2002 summer where appeared the grounds of many constructions identificated with medieval hermit of Santa Isabel situated around Jaen. It has tried to contrast the registered archaelogical information, with diverse informed documents.
\end{abstract}

KEY WORDS: Hermit, Medieval, Crypt. cipales puertas: la de Martos' y la del Aceituno (ULIERTE, 1990), además de emplazarse junto a una importante vía de comunicación que enlazaba Jaén con Córdoba. No se tienen noticias de ocupación en esta zona hasta época reciente.

El conjunto excavado se ha identificado provisionalmente con la antigua ermita de Santa Isabel, a la que aparece ligada un cementerio.

La Puerta de Martos era una de las importantes de la ciudad musulmana y la única medieval conservada hasta época moderna, hasta su demolición en el año 1895. De ella se ha conservado una fotografía que formaba parte del álbum de visitas locales que se ofreció a Isabel II con motivo de su visita a Andalucía. Esta puerta estaba constituida por un lienzo de muralla y dos torreones adyacentes, estructuras que todavía perduraban en 1978. Torres Balbás rescató esta imagen de las colecciones del museo de la Alhambra y la publicó en la revista "Arquitectura" de la que la tomó Cazabán en 1930 para su crónica mensual "Don Lope de Sosa". (ESLAVA, 1988).

Recientemente se ha llevado a cabo una Intervención Arqueológica de Urgencia en una parcela de la C/ Puerta de Martos en Jaén, en la que se han hecho hallazgos de gran importancia en cuanto a la ubicación de la citada Puerta (HERRANZ, 2003). 


\section{LA INTERVENCIÓN ARQUEOLÓGICA}

El solar estudiado se encuentra en la ladera del Cerro de Santa Catalina, su ubicación en Nivel de Protección $C^{2}$ y la inminente construcción de un residencial, hizo necesaria la intervención de urgencia.

Debido a su catalogación dentro de la zona de Cautela Arqueológica, algunos sectores de la parcela fueron excavados íntegramente con medios mecánicos, estudiándose tan sólo con un metodología adecuada aquellos sectores donde se detectaron restos arqueológicos. Además el ritmo de trabajo fue marcado por las necesidades de la edificación, por lo que hubo cierto desorden en lo que se refiere al desarrollo de las investigaciones.

La primera estructura que se documentó (Complejo Estructural I) pertenece a un espacio habitacional de forma aparentemente cuadrada, de unos 8 por 9 metros de lado aproximadamente, aunque no se ha documentado al completo debido a que los muros continuaban, por debajo del acerado, hacia la calle. Los restos de los muros conservados presentan una técnica constructiva bastante tosca, tienen casi un metro de grosor y descansan sobre la base geológica aunque existen algunas diferencias entre ellos: El muro I es más ancho debido a que ha sido revestido con varios refuerzos, los cuales conservan una altura inferior a la del muro primitivo y sobre ellos aparece un nivel de suelo. Presenta un aparejo de mampostería con piedras irregulares de distinto tamaño, a veces, calzadas con tejas y ladrillos. El Muro 2 tiene un primer tramo de $4 \mathrm{~m}$. de longitud, y un segundo girando hacia el Este con $2 \mathrm{~m}$. y un tercero que de nuevo gira al norte con I m. haciendo un pequeño recodo para unirse al muro Norte. Se trata de un muro de mampostería que presenta un fuste reutilizado entre las piedras. Por su parte el Muro 3 tiene una longitud de 9,5 m. y alterna la citada mampostería con cajones de tapial. Finalmente el Muro 4 compartimenta la estructura y presenta un vano que podría ser un acceso, aunque en algún momento perdió esa función pues está sellado con piedras. (Ver Lam. 9 y Fig. 5)

Entre los materiales que se han registrado aparecen diversos fragmentos de cerámica: platos, jarras, etc. casi toda vidriada en tonos verdes, blancos y marrones melados, así como olambrillas con decoración en arista, que presentan una cronología que abarca desde el siglo XVII hasta el siglo XIX.

La segunda estructura documentada engloba los Complejos Estructurales 2 y 4.

En primer lugar se documentó el Complejo Estructural 2 formado por los restos de una pared enlucida con yeso de unos $5 \mathrm{~m}$. de longitud y unos $40 \mathrm{~cm}$ de altura, que se apoyaba directamente sobre la roca; a éste se adosaban unas escaleras de mampostería de unos 70 $\mathrm{cm}$ de ancho de la que se conservaban dos peldaños, seguidas de una pared enlucida con yeso de $80 \mathrm{~cm}$ de longitud, muy deteriorada, ambas estructuras apoyaban sobre un nivel de suelo que aún conservaba algunas baldosas, blancas y verdes. La pared de yeso se une con un muro del Complejo Estructural 4, pudiendo tratarse de unas dependencias relacionadas con este. (Ver Fig. 5)

El Complejo Estructural 4 está compuesto por un edificio de planta rectangular que ha sido documentado parcialmente y un patio que conservaba un empedrado. Sus muros tienen un grosor de unos $80 \mathrm{~cm}$ y muestran una técnica constructiva que alterna mampostería y ladrillo, presentando un revoco de yeso que ha desaparecido en varias zonas. El muro I ( Fig. 4 y Lám. 7) tiene una longitud de 9 m y con-

2 En la Zonificación Arqueológica de la ciudad de jaén la parcela se encuentra en nivel de Protección Arqueológica C: Cautela Arqueológica, "...estos lugares requieren la presencia de especialistas mientras duren los trabajos de movimientos de tierra, de manera que se asegure la integridad de los restos antiguos que pudieran descubrirse en el transcurso de los trabajos de remoción. La aparición de nuevos datos sobre el interés arqueológico de esos lugares conllevaría la inmediata recatalogación de los mismos y, por tanto, deberán seguir el tratamiento pertinente de acuerdo con el nuevo nivel de protección reconocido" (CASTRO, 1987:339). 
serva tres contrafuertes al exterior; mientras que en el interior se documentó un zócalo de alicatado de tradición mudéjar, con figuras geométricas que formaban dibujos poligonales y romboideos, así como cenefas de lacería, ( Ver Fig. 6 y Lám. 8) contiguo a éste se localizó una columna de ladrillo adosada sobre la que se abría una hornacina. Esta es la única zona donde se ha conservado este tipo de decoración, aunque hay que tener en cuenta que en la mayor parte del espacio nos encontramos en un nivel de cimentación. Hacia la mitad del muro se constató la presencia de un pilar cuadrado adosado a él, que conectaba con el contrafuerte central exterior y siguiendo hacia el Este aparecieron varios arcos ciegos seguramente construidos con la finalidad de aguantar los distintos empujes de la cubierta y los mismos muros.

El muro 2 tiene una longitud de 4,5 m., y al igual que el anterior, también presenta la misma técnica constructiva y semejantes arcos ciegos de ladrillo, donde observamos el revoco de yeso deteriorado y un vano que funcionaría como acceso hacia una planta superior no conservada, sin embargo si se ha documentado un nivel de suelo bajo este acceso que podría tratarse de un espacio subterráneo. (Ver Fig. 4).

Al patio se accedería por el Norte y tenía unas dimensiones de 4'5 por $3 \mathrm{~m}$ presentando un empedrado formando dibujos semicirculares. El muro que rodea el patio conectaba con el Complejo estructural 2, de ahí la posibilidad de que se trate de alguna dependencia relacionada con este espacio.

El Complejo Estructural 3 se localiza al Este del Corte I, se trata de una estructura rectangular semisubterránea de unas dimensiones aproximadas de $4 ` 5 \times 3 ` 5$ metros, con una cubierta abovedada de ladrillos. Se accedía a ella por la cara Oeste que presentaba una entrada central de unos 70 centímetros de ancho con tres peldaños, el primero destrui- do, el segundo muy deteriorado y el tercero, en el interior, destruido del que queda tan sólo una marca en la pared. Dentro se conservaba un banco corrido que rodea toda la estructura, excepto por la cara del acceso. Las paredes son de mampostería y revocadas con yeso. La bóveda se apoyaba en su cara norte en un muro de contención, pues existe un importante desnivel en la parcela.

Del interior hallamos una cabeza de yeso de un león que en la que se apreciaban restos de policromía y pan de oro, y sobre el banco corrido recogimos diversos restos de fauna y escasos restos humanos (tan sólo algunas costillas).

Es bastante posible que este espacio funcionase como cripta funeraria ${ }^{3}$. Junto a esta estructura se exhumaron varios complejos funerarios.

\section{COMPLEJOS FUNERARIOS}

Los restos humanos aparecieron en el transcurso de los movimientos de tierra, derivados de las obras que se estaban llevando a cabo en el solar, se localizaron bajo un nivel de escombros que en esa parte de la parcela alcanzaba los dos metros y medio de potencia. El hallazgo consta de cuatro sepulturas, cada uno de ellas con un número distinto de individuos.

La primera inhumación se encontraba en una fosa excavada en la roca, con orientación Oeste-Este, probablemente en posición de decúbito supino con los brazos extendidos, aunque se encontraba incompleto, tan solo se pudieron documentar las partes superiores del cuerpo (Ver Lám. I y Fig. 2) .Las partes inferiores posiblemente fueron arrasadas durante los movimientos de tierra. El individuo estaba encajado en la fosa. Sobre ésta no se localizó ningún tipo de cubierta.

Cabe destacar que sobre el tórax del individuo se encontró una hebilla de metal que

3 Una estructura similar fue documentada durante los trabajos de restauración llevados a cabo en la Iglesia de la Merced de Jaén. CASTILLO, 1999. Anuario Arqueológico de Andalucía. Tomo III. 1994:242-249. 
había alterado el color original de los huesos tornándolos en color verde. Igualmente tenía una mancha del mismo color en el cráneo (en el parietal izquierdo) que podría tratarse de un broche, o bien los restos de algún adorno como un pendiente, del que no se conservaron restos materiales.

El segundo enterramiento está formado por una fosa excavada en la roca, con la misma orientación Oeste-Este. Se trata de un enterramiento múltiple, con al menos cuatro individuos, de los cuales solo 2 (individuos 3 y 4) aparecieron prácticamente completos y en su posición original; el resto se encontraban amontonados, lo que podría deberse a una reutilización de la tumba (Ver Fig. 2).

El Individuo 2 tan solo conservaba fragmentos de las extremidades inferiores y la pelvis que aparecían depositadas sobre las piernas del individuo 3 y, por tanto, con una orientación distinta. Parece que fue depositado directamente sobre el individuo 3. Al lado aparecían dos cráneos y fragmentos de huesos amontonados a los pies del individuo 3 (Ver Fig. 2).

El Individuo 3 aparece prácticamente completo, es un enterramiento de rito cristiano con una orientación Oeste-Este. Se encontraba en decúbito supino y con las manos cruzadas sobre el pecho. Su estado de conservación era bueno excepto el cráneo. Esta inhumación estaba envuelta por una capa de color oscuro que podría corresponder a una descomposición de la madera porque durante el proceso de excavación se han hallado varios clavos de hierro que conformarían el ataúd. También aparecieron varios alfileres alrededor de su cuello, circunstancia que no volvió a darse en ninguno de los otros individuos y finalmente sobre su cintura apareció una hebilla.

El Individuo 4 apareció bajo el individuo 3 con la misma orientación (Oeste-Este) pero ligeramente desplazado hacia el sur. Al igual que el Individuo 3 se trata de un enterramiento de ritual cristiano en posición de decúbito supino con los brazos flexionados sobre el pecho, ubicado en el centro de la fosa excavada en la roca. Resulta bastante probable que este indi- viduo fuese depositado dentro de un ataúd de madera pues a la altura de la cabeza, que no se halló, se dibujaba una línea de color oscuro con un clavo de hierro en uno de sus extremos, además se encontraron clavos por todo el perímetro de la inhumación. No se hallaron restos de ningún tipo de cubierta, tan solo unos diez centímetros de tierra separaban los enterramientos de los individuos 3 y 4 (Ver Fig. 2).

El tercer sepulcro contiene sólo una inhumación (individuo 5). A diferencia de las anteriores no parece que existiera una fosa excavada en la roca; sino que se realizó en la tierra, así mismo no hay evidencias de que estuviera dentro de un ataúd como los anteriores. Presenta la misma orientación (Oeste-Este) y aparece prácticamente completo; Se define como un enterramiento de ritual cristiano en posición de decúbito supino con los brazos flexionados y las manos entrecruzadas sobre la cintura, zona donde localizamos un pequeño broche de metal. Presentaba un buen estado de conservación a pesar de no estar contenido en una fosa, aunque el cráneo tenía la parte frontal destrozada y la pelvis y las extremidades inferiores estaban bastante deterioradas, como consecuencia de la presión ocasionada por los destierros mecánicos ejecutados en el solar. (Ver Fig. 2 y Lám.2).

La cuarta sepultura contenía dos inhumaciones (Individuos 6 y 7). Como la anterior, se efectuó practicando una fosa en la tierra en la que no quedaron evidencias de la existencia de ataúd. Aparecieron incompletos, debido posiblemente a que se encontraban muy cerca de los escombros contemporáneos que rompían la base geológica en esta zona. El individuo 6 presentaba parte de la columna vertebral y de la caja torácica, parte de las extremidades superiores (cúbito y radio derechos e izquierdos), la pelvis y las extremidades inferiores. Pese a su mal estado, era evidente que mostraba un ritual cristiano (en posición de decúbito supino con los brazos flexionados y las manos entrecruzadas sobre la pelvis). El individuo 7 es el más deteriorado solo conservaba las extremidades inferiores pero por su posición parece que conformaría un enterramiento similar a los descritos (Ver Fig. 2). 


\section{LAS ERMITAS}

La conquista de la ciudad de Jaén en 1246 por Fernando III, trajo consigo una serie de transformaciones más o menos importantes, como la división administrativa de la ciudad en collaciones, denominadas con el nombre de la parroquia de la que dependía, sin embargo, se sigue ocupando básicamente el mismo espacio intramuros de que se disfrutaba antes (SALVATIERRA, 1993). Este es el momento de la creación de las capillas y ermitas en Jaén, ligadas a la introducción del culto cristiano tras la conquista. (LÁZARO 1989).

Soledad Lázaro (1989) establece una clasificación de las ermitas por su situación topográfica y las divide en las situadas dentro del recinto amurallado y las situadas extramuros. Éstas últimas las subdivide en las que están cercanas a la muralla y las que se asientan más lejos. En el extremo opuesto a la Puerta de Martos, a la salida de la Puerta de Granada se alzaba la ermita de Santa Ana. A la salida de la Puerta Barrera se situaban las ermitas de San Roque y San Nicasio, en el actual Barrio de Belén, y en el paraje de la actual alameda se levantaban las ermitas de Santa Quinteria, San Cristóbal y Nuestra Señora de la Cabeza. (LÁZARO, 1989:286).

Se conocen varias ermitas situadas extramuros de la ciudad medieval, en el arrabal de la Puerta de Martos, como la ermita de la Coronada y la de San Sebastián, ambas del siglo XIII. Sin embargo, los grandes brotes epidémicos del siglo XIV propician nuevas fundaciones, como fue el caso de San Lázaro, un lazareto dedicado a enfermos incurables. No obstante, durante el siglo XV el panorama se va ampliando y se añaden nuevas ermitas como la de Nuestra Señora de la Consolación, Santa Maria la Blanca y Santa Isabel. En el siglo XVI, el auge de nuevas devociones permitirá la fundación de nuevas ermitas como es el caso de San Antón y Nuestra Señora de la Trinidad (LÁZARO, 1989).

4 AHPJ, Sínodo Diocesano, I5II, Título, 8, Cap. I Folio, 91.
Las ermitas y las cofradías actuaban de forma similar, ambas eran asociaciones voluntarias de personas, unidas para la realización de varios fines, con una organización determinada y puestas bajo el título de un patrón (GARRIDO, 1986). Luis Coronas justifica la gran aceptación que tenían estas ermitas por ser motivo de romerías, que suponían la salida del entorno urbano para festejar a los santos o a la Virgen y a la vez distraerse en plena naturaleza. Éste es el caso de la romería de la Virgen de la Cabeza en La Alameda, que no tuvo buena fama por los excesos que en ella se cometían. Otras, como las romerías de la de la Virgen de la Peña y la de la Virgen Blanca, que tuvieron de mejor reputación. (CORONAS, 1994:285-286)

Como vemos, Jaén contó con numerosas ermitas desde tiempos medievales, sin embargo la mayoría se han transformado o han desaparecido, pero aún quedan pequeños vestigios de algunas de ellas. La Ermita de Nuestra Señora de la Peña, en el Cerro del mismo nombre. Sus restos, aunque incorporados a una casería, aún son visibles. Data de 1588. La Ermita de Nuestra Señora de la Capilla, en el paraje del Río Cuchillo. La Ermita del Hermano Lázaro, en el Cerro del Zumel, construida aprovechando el aljibe de una fortaleza islámica. La Ermita de San José, en el paraje del Arroyo de Valparaíso, hoy en estado ruinoso, o las Ermitillas de Almodóvar al pie del Cerro Almodóvar, junto al paraje del tiro Nacional (W.AA., 1985).

\section{LA ERMITA DE SANTA ISABEL}

Son escasos los datos publicados acerca de las ermitas, aunque existen algunos datos que a continuación relatamos.

En 1492 las Constituciones Sinodales realizadas por el obispo D. Luis de Osorio no mencionan nada acerca de las ermitas (RODRÍGUEZ, 198I). Sin embargo en $151 I^{4}$ en las realizadas por D. Alonso Suárez aparecen varias ermitas entre ellas la de Sancta Elisabeth, que identificamos como la de Santa Isabel, que vuelve a 
parecer en las Constituciones Sinodales de 1586 y que deja de aparecer en las de 1624.

En el año 1710 la ermita se encontraba en situación de ruina debido a los temporales. Se había hundido parte del tejado y una parte de muro. Las obras fueron sufragadas por el obispado ya que la cofradía no disponía de fondos. (Lázaro, en prensa) ${ }^{5}$.

Y Martínez de Mazas ( 1794) al mencionar la fundación en I5 I I del Convento de La Coronada, indica que se fundo primero en el arrabal fuera de la Puerta de Martos, junto a la ermita de Santa Isabel.

Una noticia similar es la que proporciona Pascual Madoz también al referirse al convento de la Coronada, "Este convento, situado en la Calle Maestra Baja, fue de religiosos Carmelitas Observantes. Se fundó primero en el arrabal fuera de la Puerta de Martos, junto a la ermita de Santa Isabel en el año de 151 I por la devoción del Obispo Don Alonso Suárez de la Fuente del Sauce ..." (MADOZ, 1988:161).

Respecto al poblamiento en el entorno de la ermita no disponemos de muchos datos. Esta zona, extramuros de la antigua ciudad medieval, había sido tímidamente poblada en el siglo XV. En las fuentes medievales encontramos documentación del arrabal de la Puerta de Martos, en el que algunos jiennenses recibieron solares para construir casas a las afueras del mismo. Sin embargo, la repoblación del espacio extramuros que existía entre las Puertas del Aceituno y Baeza no debió ser tan temprana, ya que se seguían concediendo tierras para cultivo (PORRAS, 1991).
A pesar de ello un documento del año 1872 trata de un "expediente Instruido por la obra de composición de la cañería situada en el Ejido de Santa Isabel" donde se nos explica como Dña. Ana Rodríguez, Viuda de Antonio Prieto, expone al Ayuntamiento de Jaén que quiere arreglar la cañería que lleva el agua al Pilar Nuevo, situado en el ejido de Santa Isabel para aprovechar los sobrantes para su arrendamiento ${ }^{6}$.

Por su parte A. Cazaban $(1918)^{7}$ relata el supuesto hallazgo de una virgen (que la tradición señala a finales del siglo XIII), en el lugar donde se erigió una ermita dedicada a la Virgen Coronada, y que "alrededor de ella nació un barrio extramuros que fue de los más importantes de Jaén y que tomo su nombre de otra hermita ,- de la de Santa Isabel-,cuyo origen no hemos podido investigar si fue anterior o posterior al de la Coronada." Esta fundación dio origen a un convento con el mismo nombre para dar mayor tributo a la virgen, y dice Cazaban "Estas y otras fundaciones religiosas en el barrio extramuros de Santa Isabel, dieron al mismo extraordinaria importancia y numerosa población". (CAZABAN, 1918).

En resumen la ermita de Santa Isabel ha tenido una larga permanencia en el tiempo, ya que desde su fundación en la segunda mitad del siglo $\mathrm{XV}$, siguió funcionando a lo largo de la Edad Moderna y, al menos, hasta la primera mitad del siglo XIX (NIEVES, 199I) ${ }^{8}$. Era sede de la cofradía titulada de "Santa Isabel y Santa Lucia". Desconocemos los individuos que se agrupaban en el entorno de esta cofradía, si era por razones laborales o bien por razones espirituales. Como simple apunte se ha de tener

\footnotetext{
5 Agradecemos a Dña. Soledad Lázaro Damas, gran conocedora del tema, la información que nos ha facilitado, que nos ha servido de gran ayuda para la elaboración de este artículo.

6 AHPJ, Leg 437,I Año 1872. Agrademos la ayuda brindada por D. Manolo Jódar Mena en la laboriosa búsqueda de fuentes documentales.

7 CAZABÁN LAGUNA, A., “La Virgen Coronada” Don Lope de Sosa. Jaén. 1918:44-47.

8 NIEVES CARRASCOSA, J.E., La desvinculación de la propiedad en la comarca de Jaén. 1991: 76

“...las pequeñas ermitas de Santa Isabel y San Félix, tampoco escaparon a esta primera oleada desamortizadora, enajenándoseles a ambas 5 fincas rústicas, un molino de aceite y una casa..."
} 
en cuenta que Santa Lucia tiene un especial patronazgo sobre las enfermedades de los ojos y su profilaxis y por lo tanto era la patrona escogida por los herreros, debido al instrumental con el que estos trabajaban. Respecto a Santa Isabel, ésta se relaciona con la práctica de la caridad y la asistencia hospitalaria (LÁZARO, en prensa) ${ }^{9}$.

\section{CONCLUSIONES}

Tras la excavación y después de haber recurrido a la consulta de diversas fuentes documentales creemos que los restos arqueológicos pertenecen a un edificio religioso, formado por un conjunto compuesto por el propio edificio de culto y diversas dependencias anexas y a asociadas a él, en concreto un patio exterior y una cripta, todo el conjunto habría constituido la antigua ermita de Santa Isabel.

Bajo el término "ermita" se han englobado históricamente distintas construcciones: pueden ser pequeñas capillas situadas extramuros de la ciudad, dedicadas a la advocación de un Santo Patrón, a la Virgen o algún Cristo; capillas construidas en los arrabales, que gozan de una situación intermedia entre la ciudad y el espacio rural, o bien aquellas ermitas edificadas a partir de mandas testamentarias y en donaciones particulares, reconocidas como tales por las Constituciones Sinodales. Dentro de este variado conjunto habría que destacar todas aquellas con una importante capacidad de atracción, es decir, capaces de suscitar fiestas y peregrinaciones locales centradas en el paisaje de su entorno, que generalmente son encauzadas por cofradías, existiendo una estrecha correspondencia entre la titularidad de la ermita y titularidad de la cofradía. Casi todas ellas se situaban sobre terrenos abruptos, estando circundadas por amplios perímetros de huertas (LÁZARO, 1989).

Generalmente se definen como edificios de planta sencilla y de pequeñas dimensiones. Las ermitas medievales no tenían mayor complejidad en su estructura, solían constar de una nave rectangular y un patio, como era el caso de la cercana ermita de la Virgen del Pilar hoy desaparecida, situada en el solar de la antigua "Granja-instituto agrícola de Andalucía Oriental" y la ermita de la Virgen Blanca situada en el Paraje de la Imora junto a la Carretera de Córdoba.

Durante el periodo de excavación, se pudieron recuperar paneles de alicatados de tradición mudéjar (Ver Fig. 6 y Lam.4) similares a los conservados en la ermita de Santa Ana en Torredelcampo, Jaén (Siglo XVI) (CASTILLO; CASTILLO, 1998). El revestimiento de las capillas con azulejos de esta factura, era una práctica bastante habitual en las iglesias de la ciudad, aun así es muy escasa la azulejería que se conserva, tal es el caso de la Mesa del Altar de la iglesia de la Magdalena y de la Capilla del Arco de San Lorenzo (GALERA, 1989:139-140). Pese a esto, el edificio goza de pocos alardes decorativos y arquitectónicos.

En relación con ermita existía otra estancia (Complejo Estructural I) realizada con un sistema constructivo distinto, que podría tratarse de la casa del santero (LÁZARO, 1989:297).

Respecto a la ubicación de la cripta funeraria documentada, hay que señalar que en la Edad Media la mayoría de los templos contaban con amplias criptas dispuestas en el subsuelo, en las que se depositaban los restos de los feligreses fallecidos. Incluso fue norma habitual el que cofradías y hermandades tuvieran como uno de sus fines el habilitar bajo sus capillas una bóveda de entierro en las que los cofrades difuntos eran sepultados Éstas fueron aprovechadas durante los siglos XIX y XX como vertederos gratuitos $y$ muchas de ellas acabaron por perderse. (LÓPEZ, 1990).

En definitiva, y aunque algunos aspectos no se puedan precisar, creemos que los restos documentados en la intervención pertenece-

9 Agradecemos a Dña. Soledad Lázaro Damas, gran conocedora del tema, la información que nos ha facilitado, que nos ha servido de gran ayuda para la elaboración de este artículo 
rían al edificio de culto y dependencias anexas de la antigua ermita de Santa Isabel, tanto por su ubicación, como por que la misma ya que se encuentra a escasos metros de la actual Iglesia del Barrio de Santa Isabel, levantada en 1947.

\section{BIBLIOGRAFÍA}

BACHILLER, M. | 865. Guía de Jaén para 1866. Jaén 1865.

BAZZANA, A. MONTMESSIN. 1985. La ceramique islamique du musee archeologique Provincial de Jaén (Espagne). Casa de Velázquez, Madrid. 1985:62-63.

CARDENAS MUÑOZ, A. 1997. Jaén. La mirada de un siglo. Diario Ideal. Granada. 1997

CASTILLO, J.C.; CASTILLO J.L. 1992. Los azulejos medievales de la ermita de Santa Ana de Torredelcampo. Programa de Fiestas y Romería. Torredelcampo. 1992

CASTILLO, J.C.; CASTILLO J.L. 1998. Torredelcampo paso a paso. 1998:20

CASTILLO, J.L.; MARÍN M.; PÉREZ M.C.; ZAFRA, J. 1992. "Intervención Arqueológica de Urgencia en el solar situado entre las calles, Millán de Priego, Rey D. Pedro, Horno Franco y S. Andrés. Anuario Arqueológico de Andalucía. Sevilla, 1992.

CASTRO LÓPEZ, M. 1987. "Zonificación Arqueológica de la ciudad de Jaén (avance)". Anuario arqueológico de Andalucía. Sevilla. 1987: 338-334.

CAZABÁN LAGUNA, A. 1918. "La virgen coronada". Don Lope de Sosa. Jaén 1918.

CASUSO QUESADA, R. 1998. Arquitectura del Siglo XIX en Jaén. Diputación Provincial e Instituto de Estudios Gienenses D.L. Jaén. 1998.

CORONAS TEJADA, L. 1994. Jaén, Siglo XVII. Diputación Provincial e Instituto de Estudios Gienenses. Jaén. 1994.

DÍEZ BEDMAR, M.C. 1999. El raudal de la Magdalena y el crecimiento urbano de Jaén. Ayuntamiento de Jaén. Jaén. 1999.

DOMÍNGUEZ CUBERO, J. 1989. La rejería de Jaén en el S. XVI. Diputación Provincial e Instituto de Estudios Gienenses. Jaén 1989.

GALERA ANDREU, P.A. 1989. "Algunas consideraciones sobre el arte de la cerámica en Jaén". Homenaje al profesor Alonso Sancho Sáez. Universidad de Granada. 1989: |37-145.

GARCÍA LORITE, F. 200I.Jaén: 100 años de historia (19002000). Librería Técnico Universitaria Gutiérrez, D.L. Jaén. 2001 .
GARRIDO AGUILERA, J.C. 1986. "Un aspecto de la religiosidad popular y asistencia social gienense en los ss. XV y XVI: Las Cofradías". B.I.E.G. N I27. 1986: 53-76.

HERRANZ, A.; ARIAS, F. 2003. En prensa.

LÁZARO DAMAS, Ma S. 1988. Desarrollo histórico del casco urbano de Jaén hasta el 1600. Jaén.

LÁZARO DAMAS, Ma S. 1989. "Ermitas y Santuarios de la ciudad de Jaén en el siglo XVI" Antropología. La religiosidad popular III. Hermandades, Romerías y Santuarios. Anthropos. Barcelona. 1989.

LÓPEZ PÉREZ, M. 1990. "Cementerios. La ciudad perdida (II)". En prensa. Diario /deal. Domingo 4 de Noviembre de 1990. Granada. 1990: 9.

LÓPEZ PÉREZ, M y LARA MARTÍN-PORTUGUÉS, I. 1993. Entre la guerra y la paz (I808-/8/4). Universidad de Granada. Granada, 1993.

LÓPEZ MURILLO, J. 1999. Jaén en blanco y negro: Introducción para una historia de la fotografia en Jaén 1860-1975. Ed. Soproarga, D.L. Jaén. 1999.

MARTÍNEZ DE MAZAS, J. 1978. Retrato al natural de la ciudad de Jaén. I 794. Reed. Albir. Hospital De Llobregat, Barcelona, 1978.

MADOZ, P. 1988. Diccionario geográfico-estadístico-histórico de España y sus posesiones de ultramar. Madrid I8451850. (Edición facsímil 1988).

NIEVES CARRASCOSA J.E. 1991. La desvinculación de la propiedad en la comarca de Jaén durante la primera mitad del siglo XIX (| 798- | 845). Jaén. I99|.

OLIVARES MORENO, A; PALAZÓN PALAZÓN, P. 1996. La ciudad de Jaén a través del plano: Un recurso didáctico en el estudio de la Geografia urbana. Centro de profesores D.L. Jaén, 1996.

ORTEGA SAGRISTA, R. 1956. "Historia de las cofradías de pasión y de sus procesiones de Semana Santa en la ciudad de Jaén. (ss. XVI-XX)". B.I.E.G. No I0. 1956:25.

ORTEGA SAGRISTA, R. 1983.

"Historia de la Cofradía de la Transfixión y Soledad de la Madre de Dios" B.I.E.G N | | 3. 1983: 22-43.

PARDO CRESPO, J.M. 1978. Evolución e historia de la ciudad de Jaén. Jaén, 1978.

PÉREZ, M.C; HORNOS, F. y ALCÁZAR, E.M., 1995. "EI proyecto de Arqueología Urbana'93: Un instrumento de conocimiento e intervención para la ciudad de Jaén". Arqueología y territorio Medieval., $N^{\circ} 2$. Universidad de Jaén. 1995:155-176.

PORRAS ARBOLEDAS, P.A. I99I. "El poblamiento de los arrabales de Jaén bajo los Reyes Católicos". Senda de los huertos. N²1. Jaén. 1991: 79-93.

RODRÍGUEZ MOLINA, J. 1981. "Sínodo celebrado en la Iglesia de Jaén en I492". Instituto de Estudios Gienenses. 1981. 
ROMERO DE TORRES, E. 1913. Catálogo de los monumentos histórico y artísticos de la provincia de Jaén. Jaén. 1913.

SALVATIERRA CUENCA, V. 1993. "Jaén entre los siglos XIII y XIV. La formación de la ciudad cristiana". Revista del Centro de Estudios Históricos de Granada y su Reino. No 7, Segunda época. Granada. 1993:149-167.

SALVATIERRA ,V.; PÉREZ, M.C.; CASTILLO, J.L.; ALCÁZAR, E.M.; CANO, L.(1993). "Formación y evolución de una ciudad islámica: Jaén", IV Congreso de Arqueología Medieval Española, Tomo II. Alicante. 1993:87-94
SENDA DE LOS HUERTOS, 1995. "Las rentas de la ermita de San Lázaro para el hospital de la Santa Misericordia". Senda de los Huertos No 39. A.H.M.J. Actas. Jaén, 1995: 44.

SILVA MORA, A. 1986. Jaén en 100 fotos. Caja General de Ahorros y Monte de piedad de Granada. Granada. 1986.

ULIERTE, L. 1990. Jaén, la ciudad y su historia. Granada.

V.AA. 1985. Guía monumental de la ciudad de Jaén y su término. Instituto de Estudios Gienenses. Jaén. 1985

V.AA. 2000. Jaén entre dos siglos (1875-1931). 2000. Museo Provincial de Jaén. D.L. Jaén. 2000. 


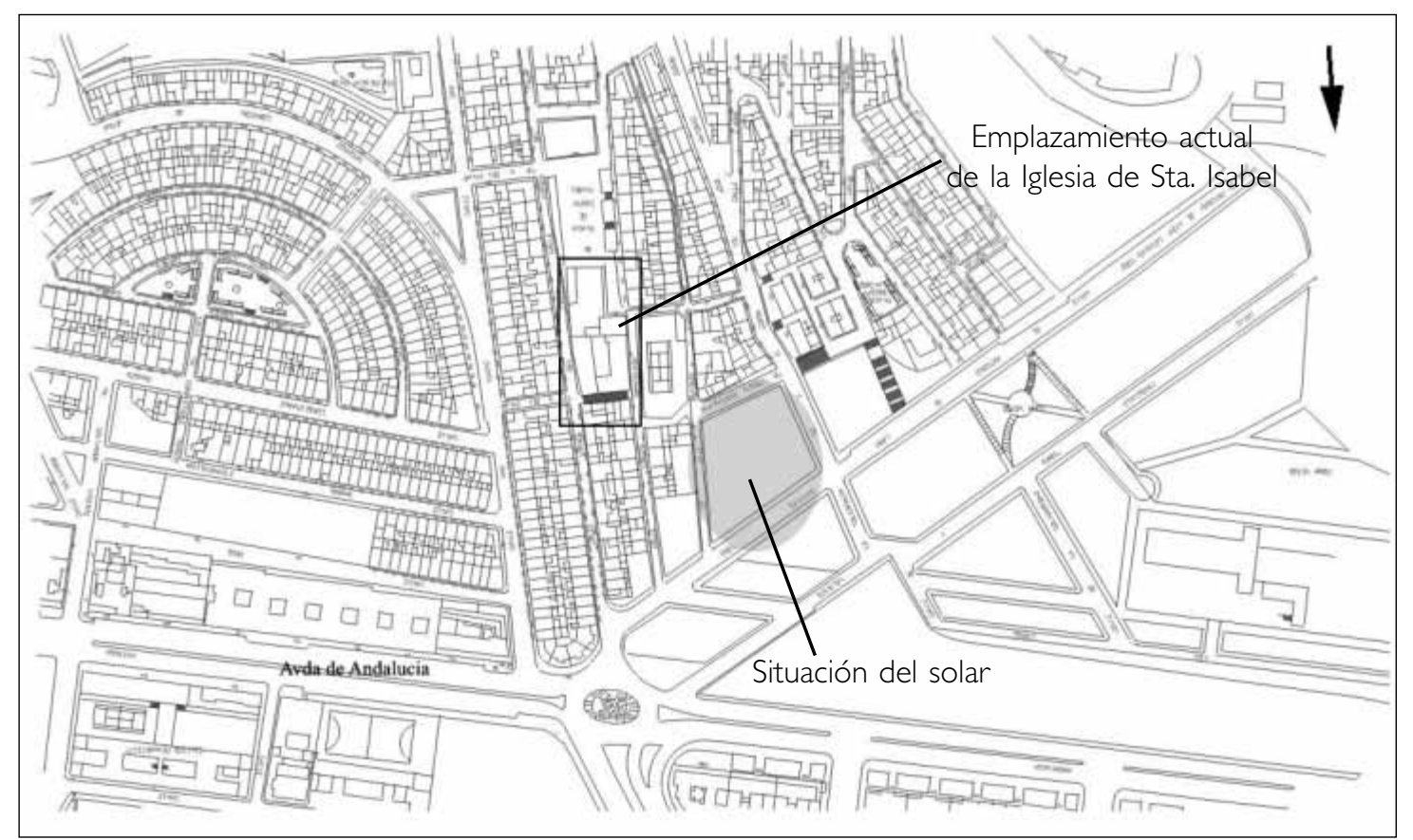

Fig. I. Situación del solar

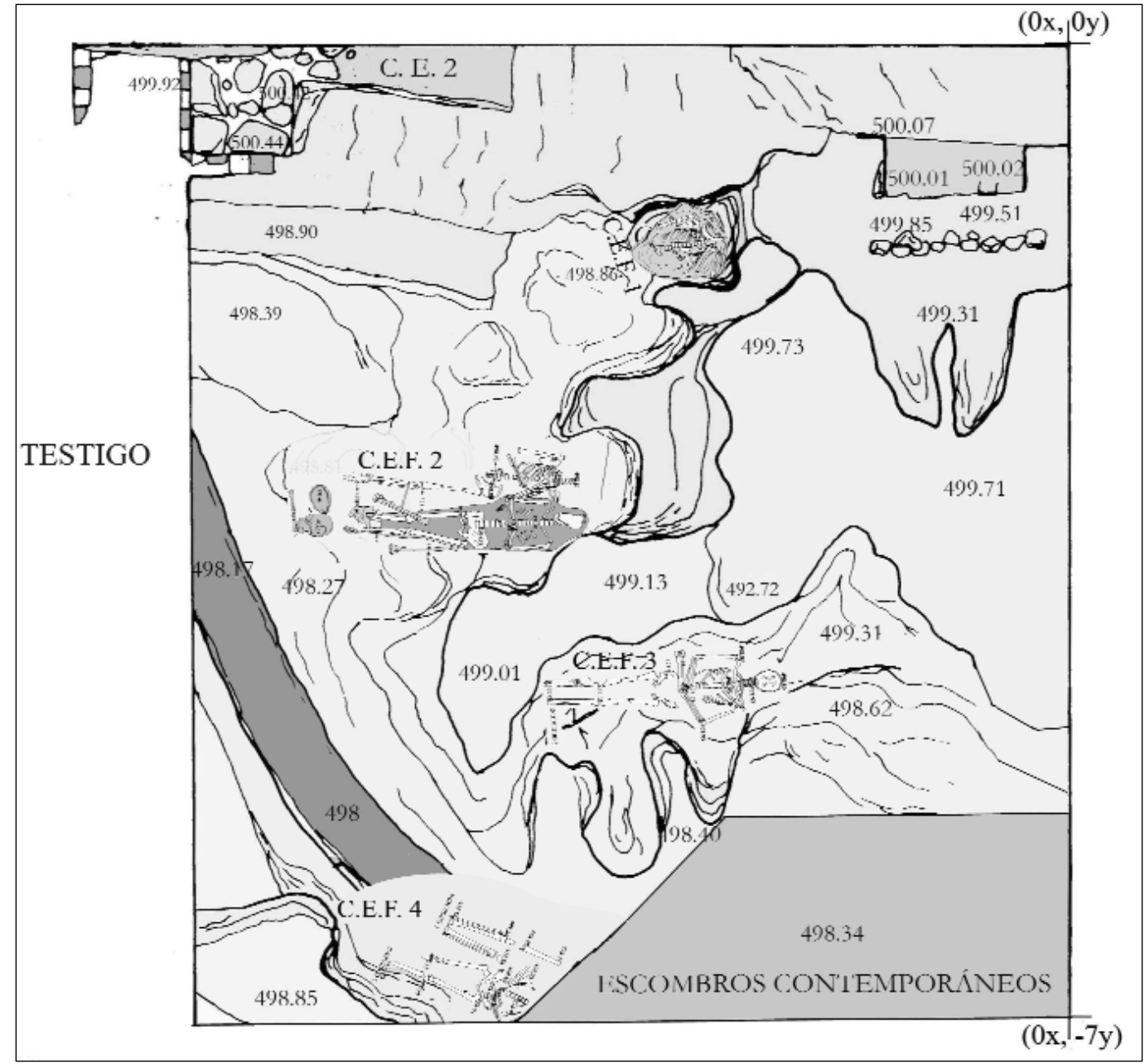

Fig. 2. Complejos estructurales funerarios 


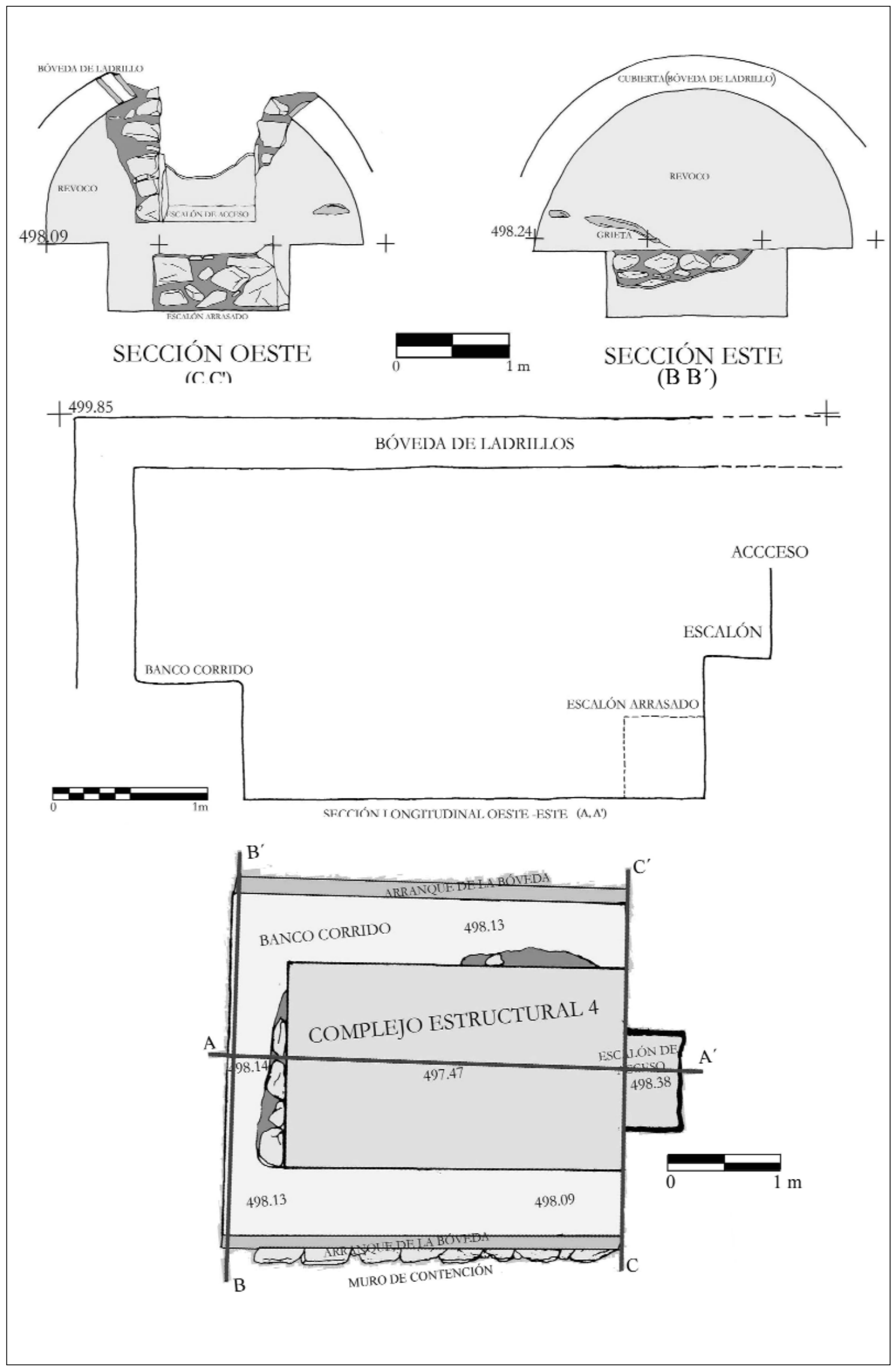

Fig. 3. Planta y secciones del complejo estructural 3 


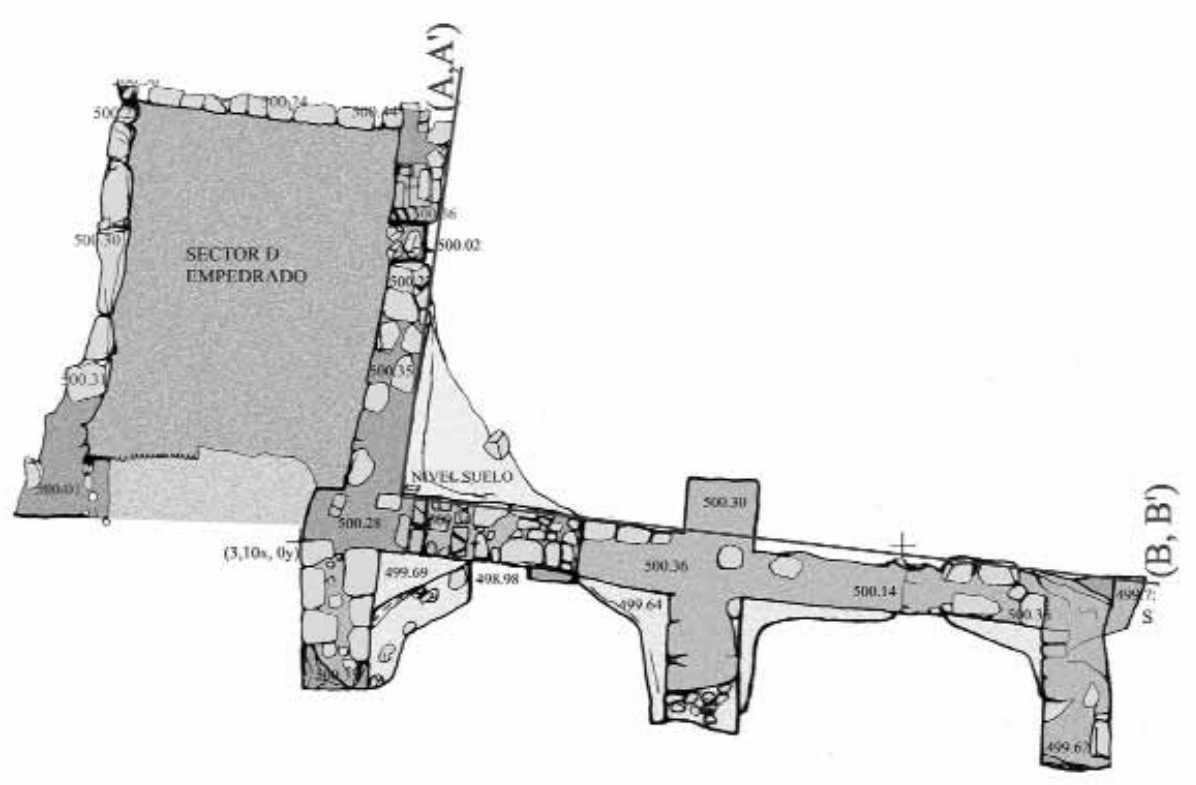

PI.ANTA DFI. COMPI.FIO FSTRISCTIJRAI 4
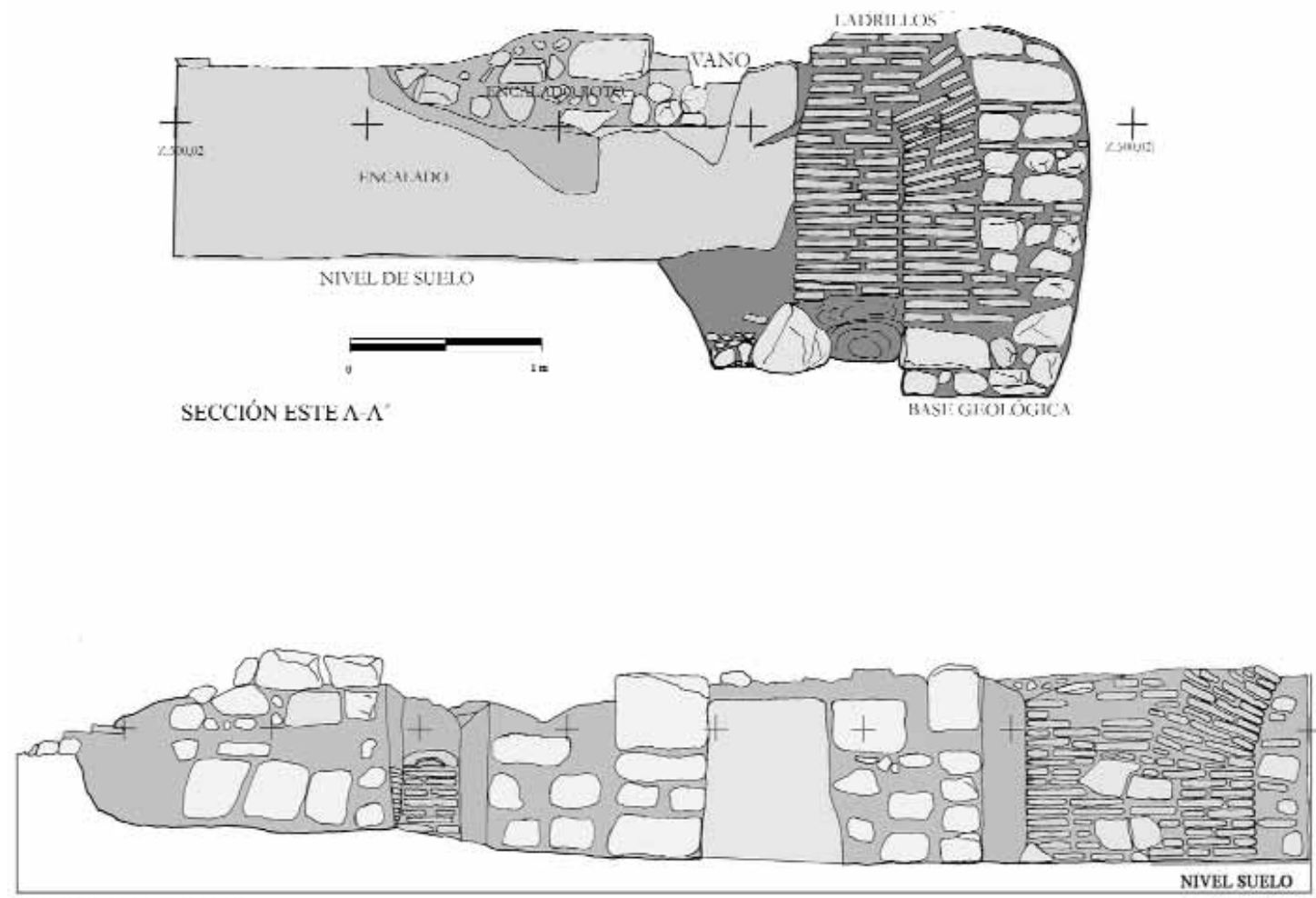

SECCIÓN NORTE (B,B')

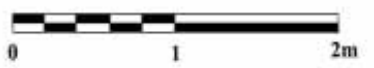

Fig. 4. Planta y secciones del complejo estructural 4 


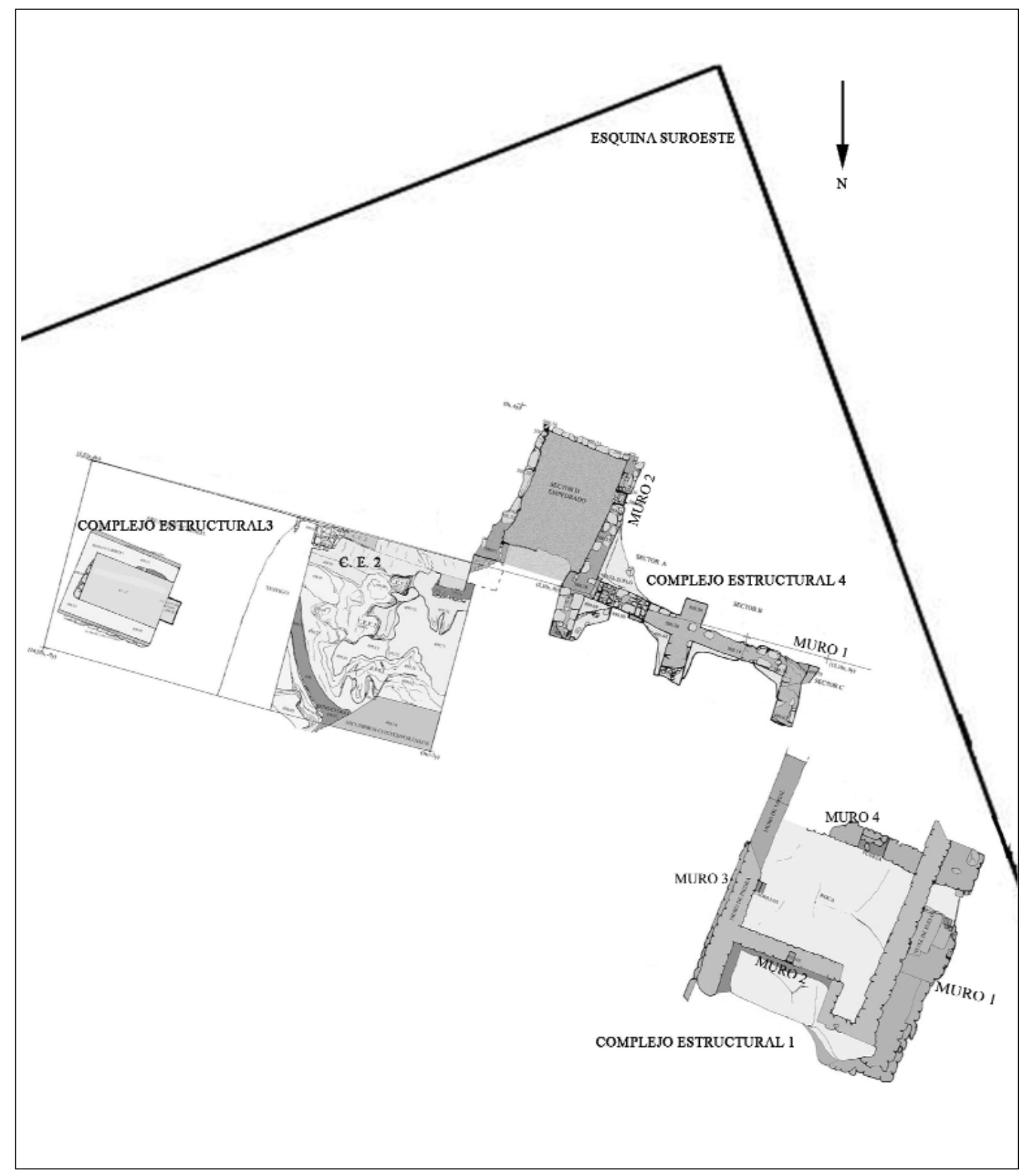

Fig. 5. Situación de los complejos estructurales 


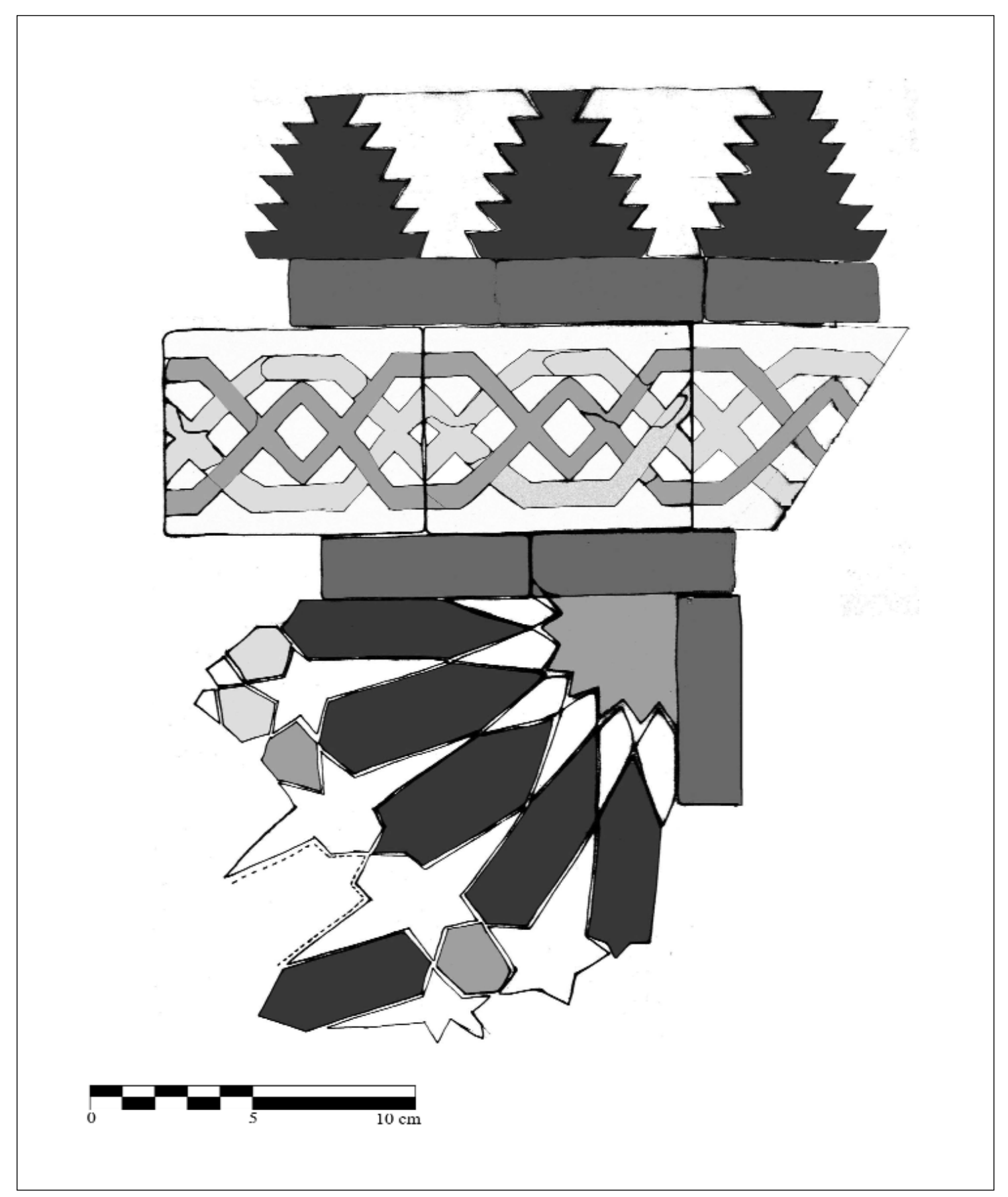

Fig. 6. Alicatado de tradición mudéjar 

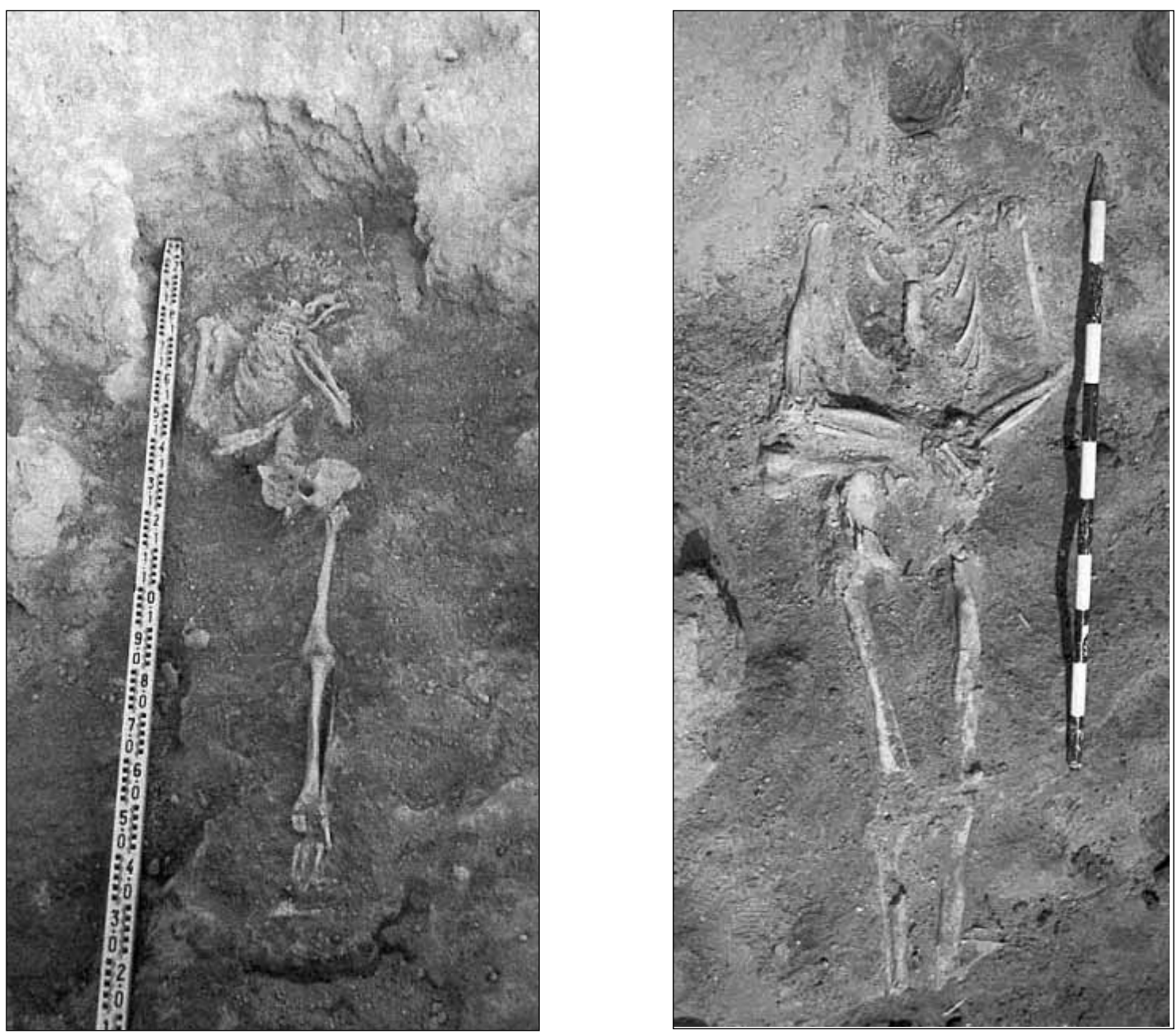

Lam. I. Individuo I

Lam. 2. Individuo 5

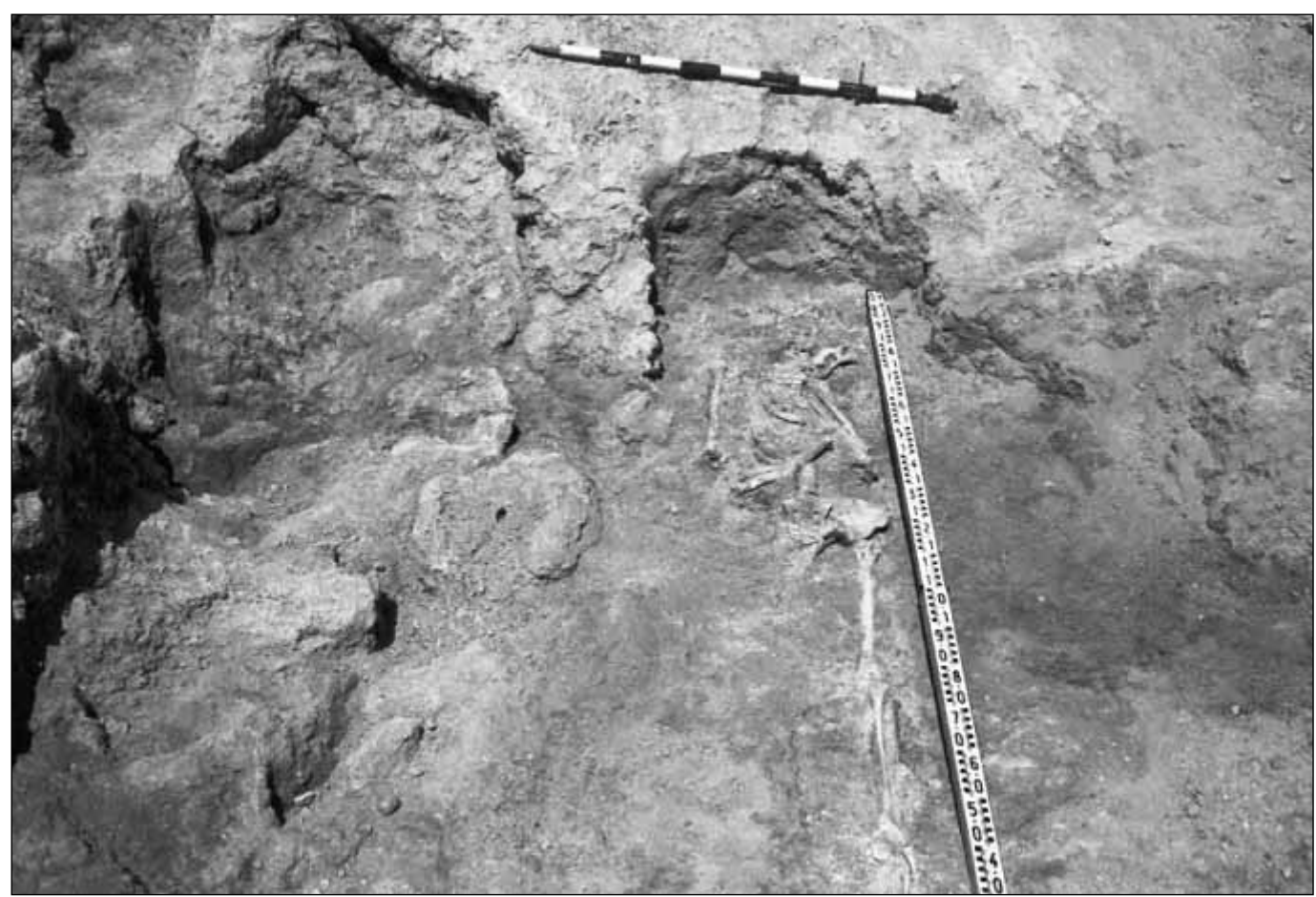

Lam. 3. Vista general del Complejo Estructural Funerario 2 


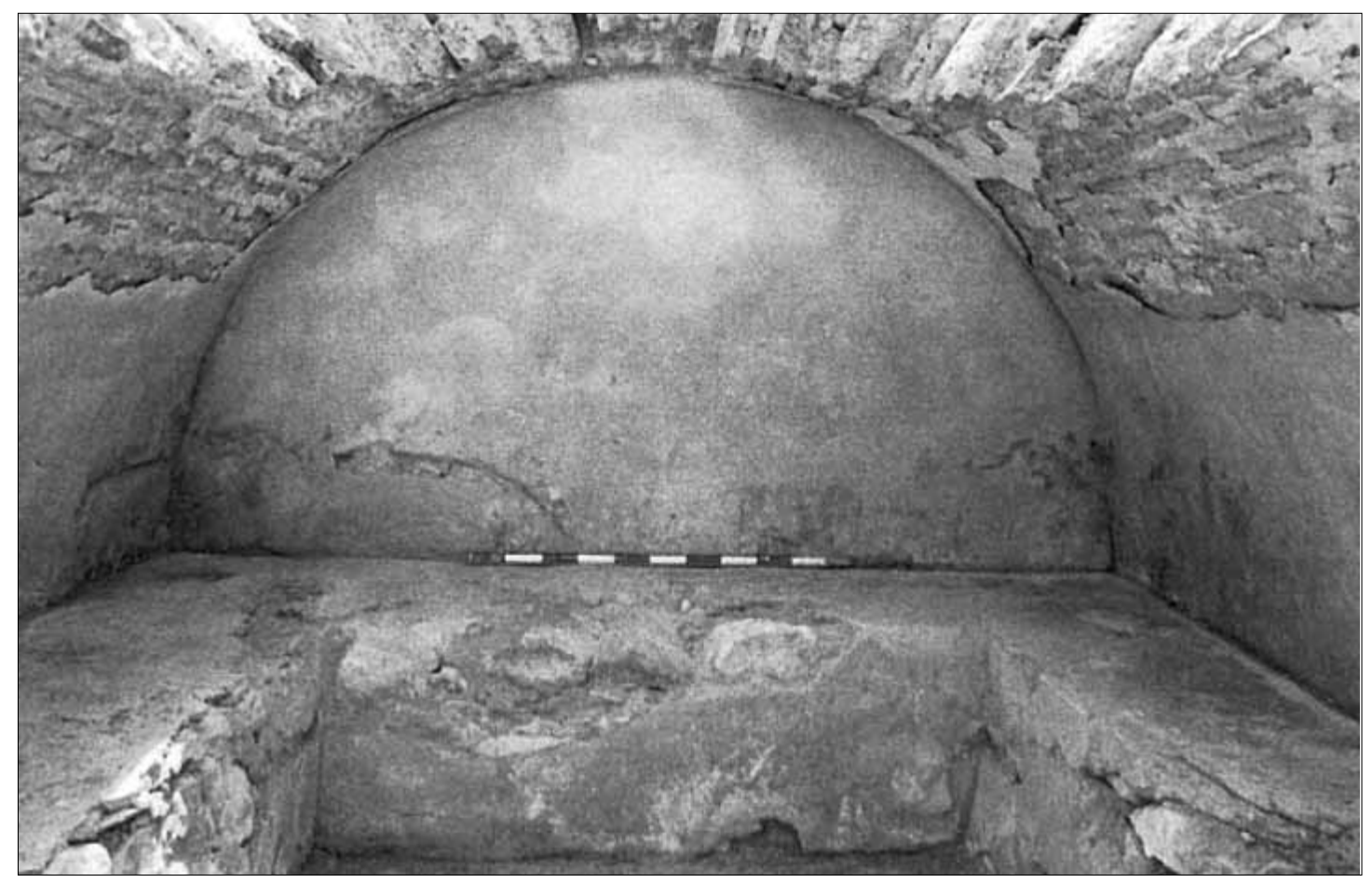

Lam. 4. Interior del Complejo Estructural 3

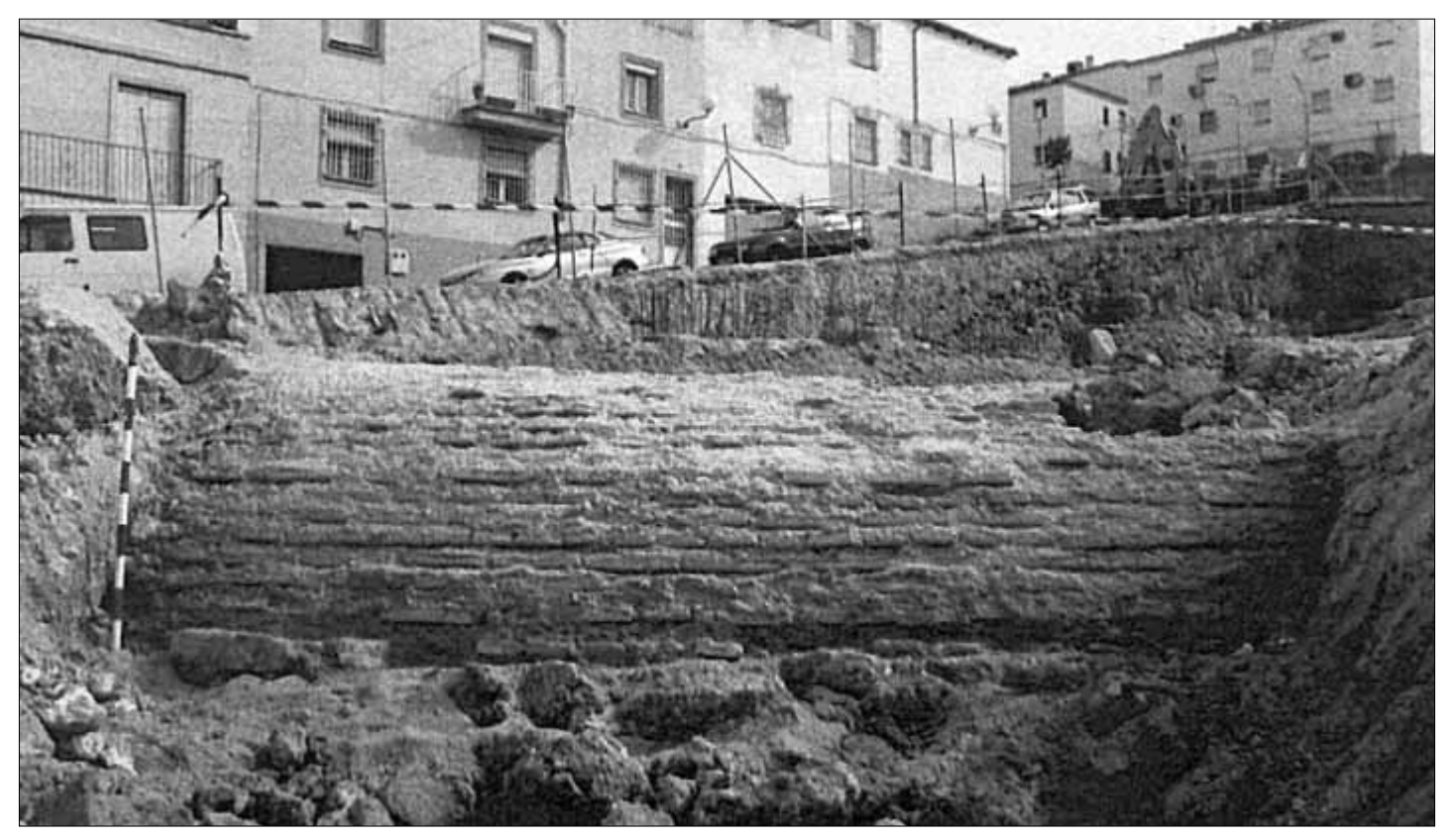

Lam. 5. Vista de la cubierta abovedada del Complejo Estructural 3 


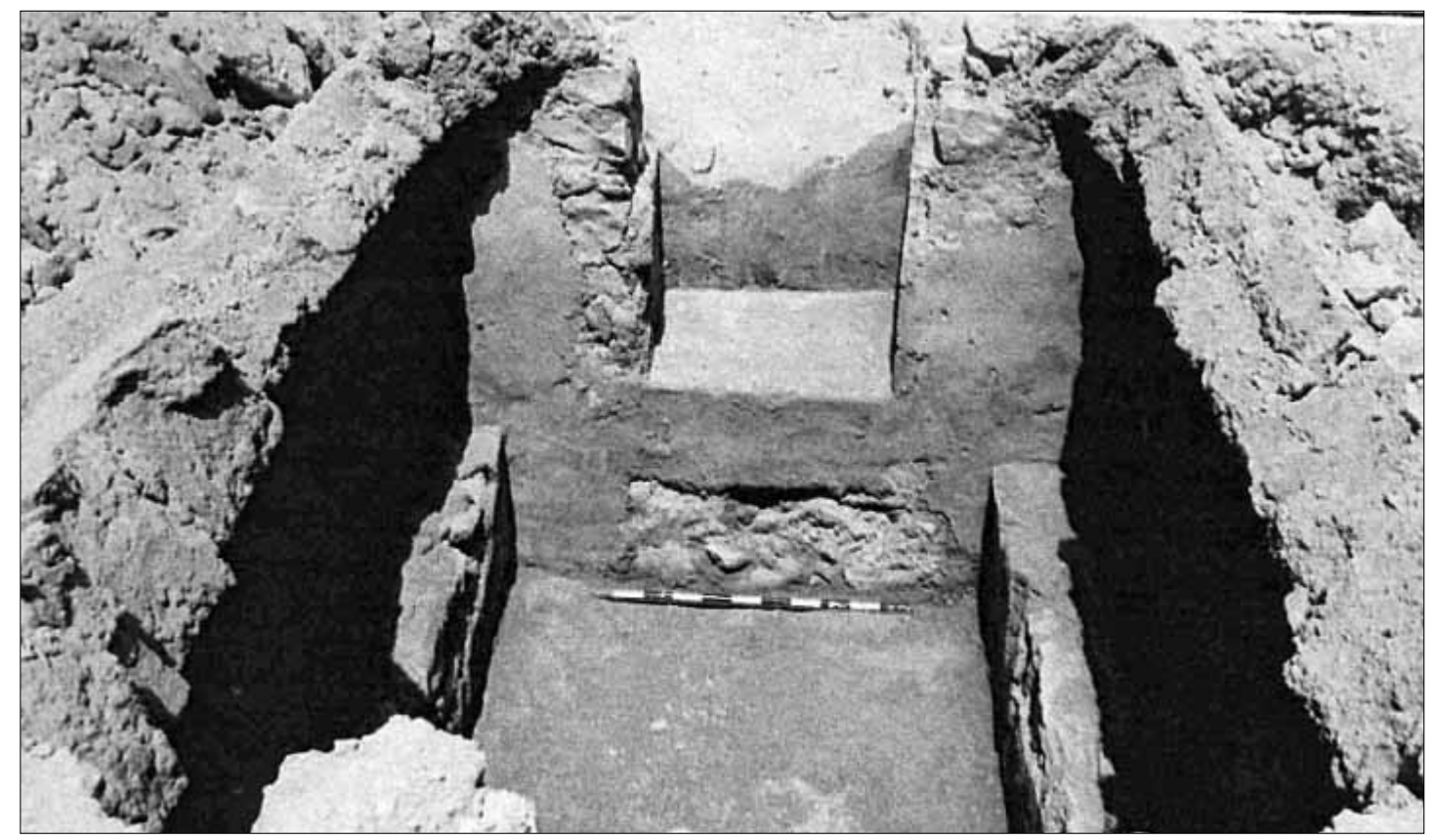

Lam. 6. Acceso escalonado del Complejo Estructural 3

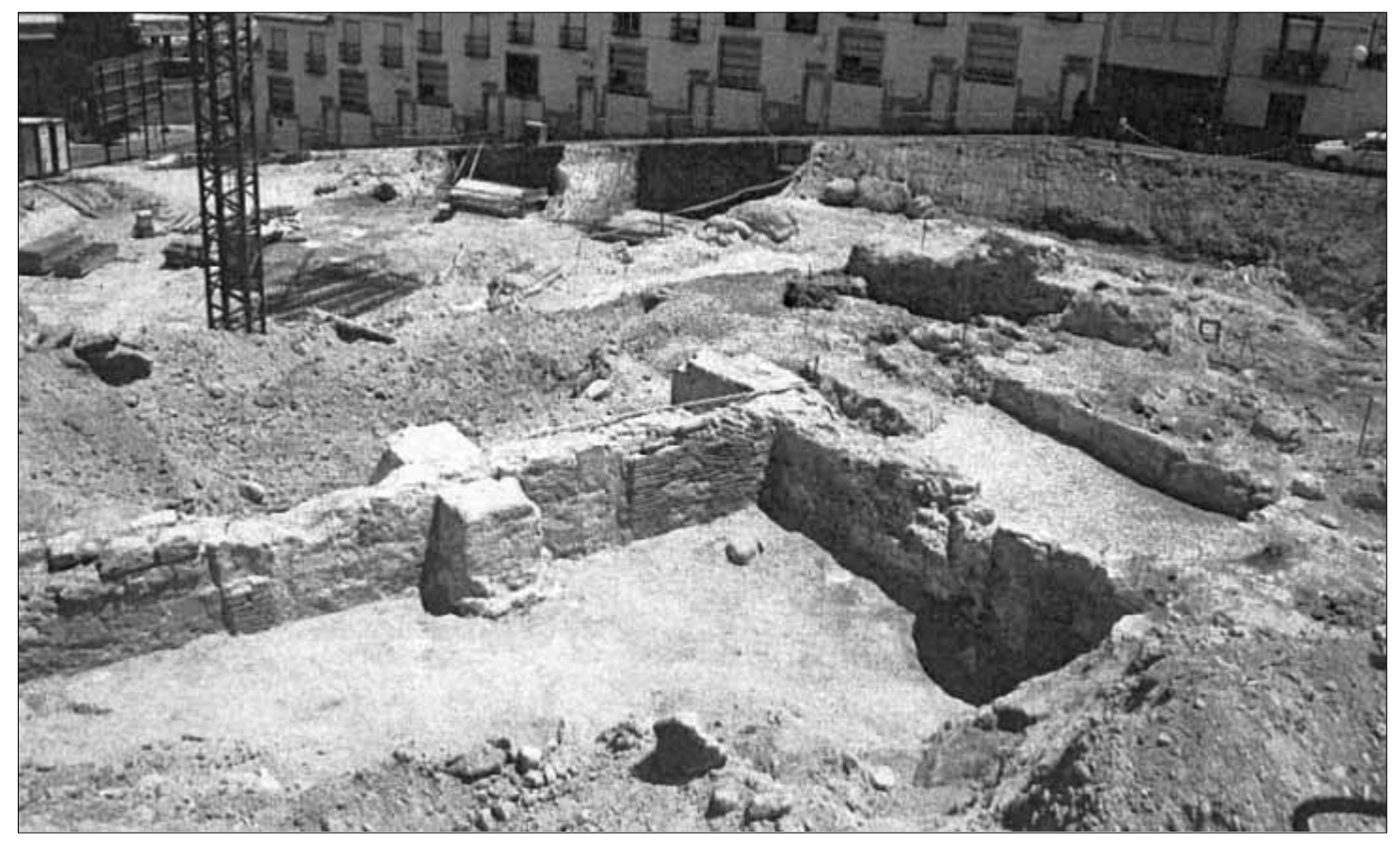

Lam. 7. Vista general del Complejo Estructural 4 


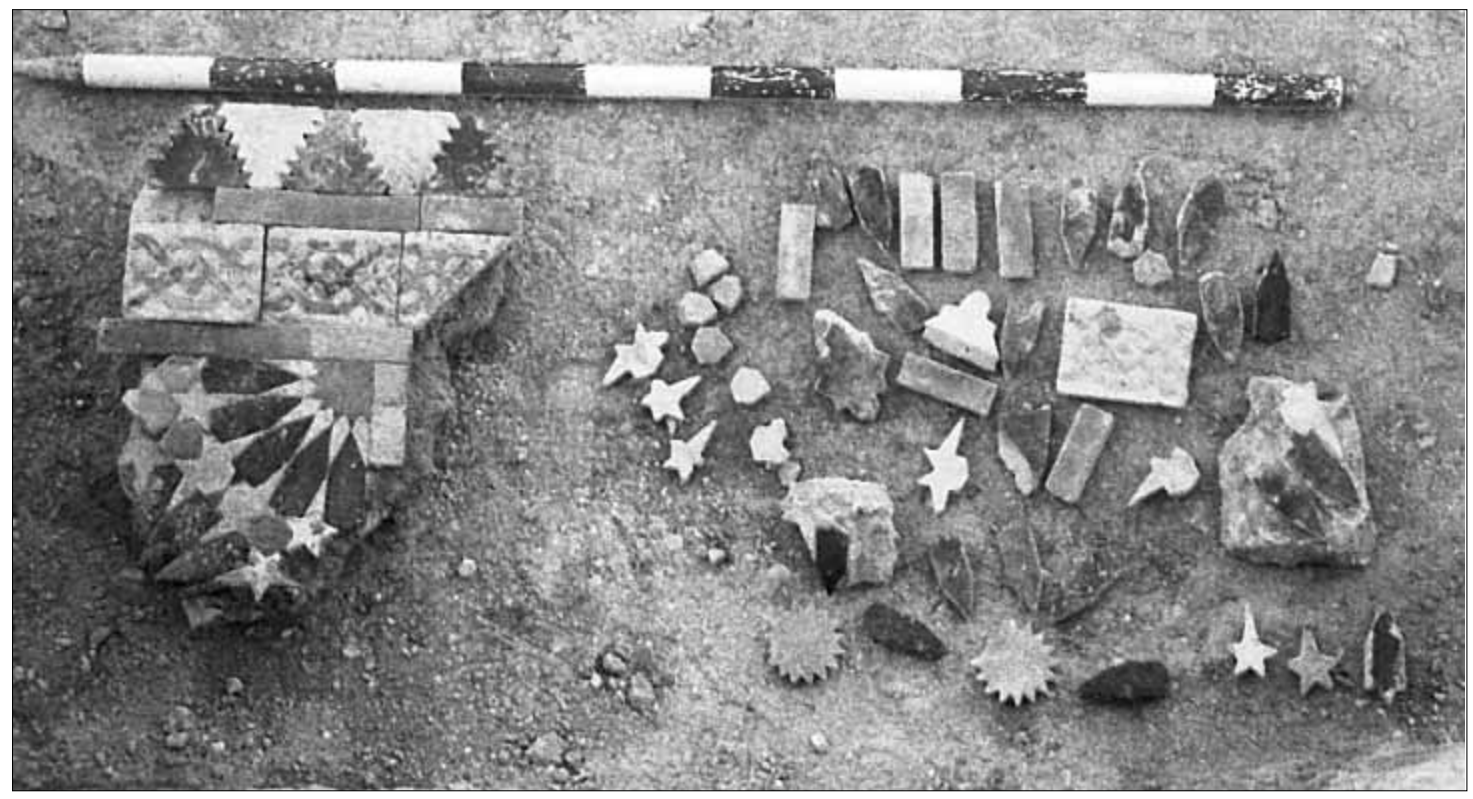

Lam. 8. Alicatado de tradición mudéjar

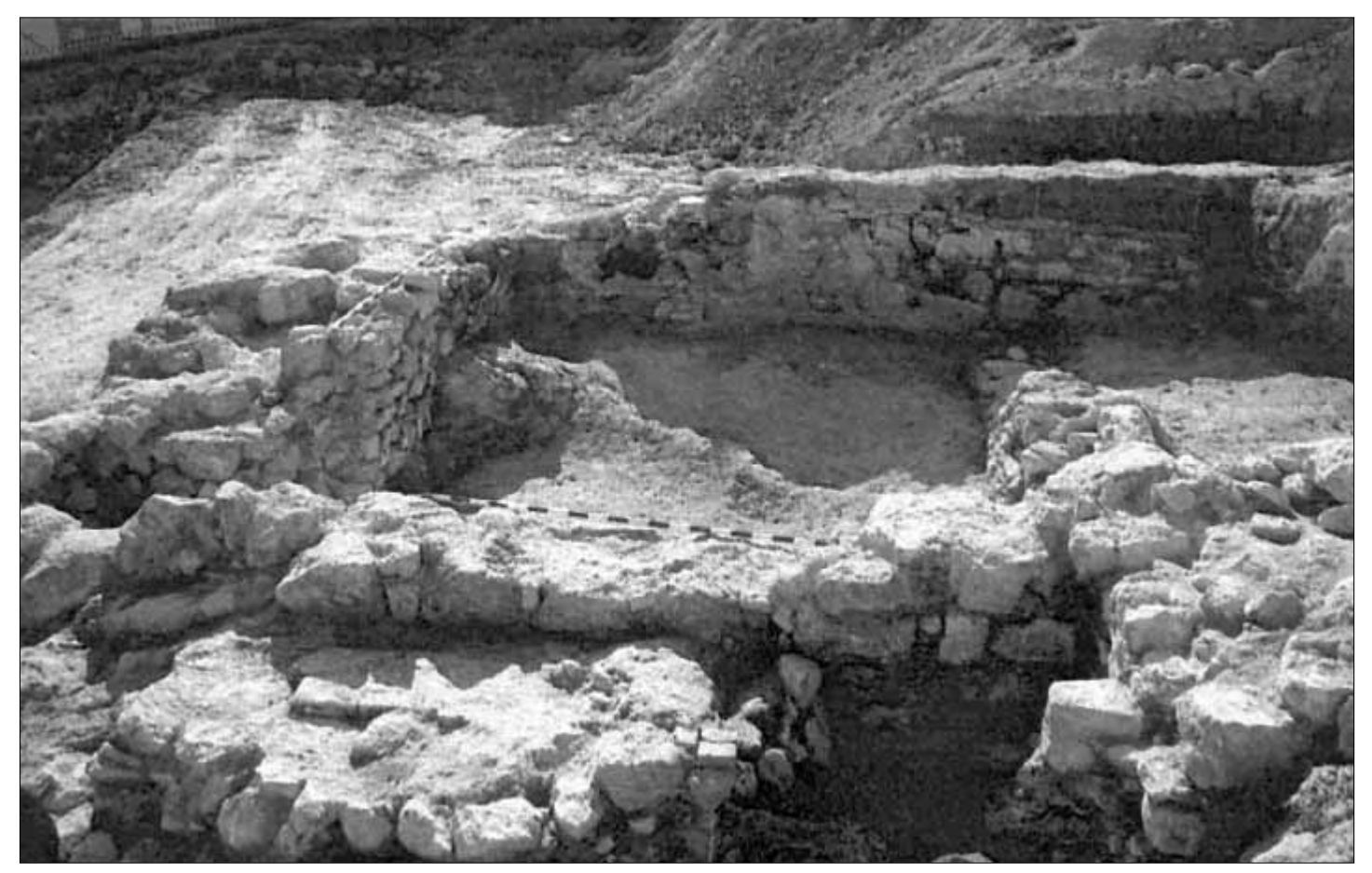

Lam. 9. Vista general del Complejo Estructural I 